\title{
Ventricular Repolarization: Epidemiology and Clinical Correlates among Type-2 Diabetics with Uncontrolled Arterial Hypertension in Western Region of the Republic of Macedonia
}

\author{
Ylber Jani ${ }^{*}$, Sotiraq Xhunga ${ }^{2}$, Artur Serani ${ }^{2}$, Bekim Pocesta ${ }^{3}$, Fatmir Ferati ${ }^{4}$, Dali Lala ${ }^{5}$, \\ Agim Zeqiri ${ }^{6}$, Atila Rexhepi ${ }^{4}$ \\ ${ }^{1}$ Private Health Institute, "Heart Diagnostica”, Debar, Republic of Macedonia \\ ${ }^{2}$ Department of Cardiology Medical Center, Dures, Republic of Albania \\ ${ }^{3}$ Department of Cardiology, Faculty of Medicine, "Ss Kiril and Metodij" University, Skopje, Republic of \\ Macedonia \\ ${ }^{4}$ Department of Internal Medicine, Faculty of Medicine, Tetovo, Republic of Macedonia \\ ${ }^{5}$ Private Health Institute of Family Medicine "Florenc", Tetovo, Republic of Macedonia \\ ${ }^{6}$ Department of Internal Medicine, General Hospital "DR Ferit Murat", Gostivar, Republic of Macedonia \\ Email: ylber_jani@hotmail.com
}

Received 15 April 2016; accepted 18 June 2016; published 21 June 2016

Copyright (C 2016 by authors and Scientific Research Publishing Inc.

This work is licensed under the Creative Commons Attribution International License (CC BY).

http://creativecommons.org/licenses/by/4.0/

(c) (1) Open Access

\section{Abstract}

This study aimed to describe the epidemiology of repolarization dispersion (QT dispersion and Tpeak-Tend dispersion) and further describe their associated clinical correlates among uncontrolled arterial hypertension in type-2 Diabetics patient, in western region of the Republic of Macedonia. Abnormal ventricular repolarization is associated with increased cardiovascular risk. Data relating to the frequency of increased repolarization dispersion, among uncontrolled arterial hypertension in type-2 Diabetics patient in western region of the Republic of Macedonia, are scarce. A total of 600 patients were enrolled into this observation study. Study participans were selected among primary care patient, who were receiving ongoing care for diabetes mellitus and hypertension during 1 calendar year. Twelve lead resting electrocardiography, QT, QTc, TpeakTend-intervals and dispersions, were determined manually, and were compared between groups. Patients with uncontrolled BP have greater frequency of: prolonged QTc.max.interval, $\mathbf{6 1 . 3 \%}$ vs.33.6\%; $p=0.0005)$, prolonged Tpeak-Tend interval $(65.3 \%$ vs. $34.7 \% ; p=0.005)$, increased dispersion of QTc. interval $(65.9 \%$ vs. $34.1 \%$; $p=0.00)$, increased disperion of Tpeak-Tend 
interval $(65.5 \%$ vs. $34.5 \%$; $p=0.002)$. Females with uncontrolled BP have greater frequency of: increased dispersion of QTc. interval $(61.2 \%$ vs. $38 \% ; p=0.02)$, increased dispersion of TpeakTend interval $(63.1 \%$ vs. $31.5 \%$; $p=0.008)$. Hypertensive diabetic patients with uncontrolled BP and abnormal ventricular repolarization have greater BMI $(p=0.000 ; 95 \%$ CI 3.849 - 7.871), longer duration of D.M ( $p=0.000 ; 95 \%$ CI 1.600 - 1.981), longer duration of arterial hypertension ( $p=$ $0.000 ; 95 \%$ CI $1.468-1.850)$ and less controlled glycemia $(p=0.000 ; 95 \%$ CI $1.556-3.004)$. Frequency of increased set of electrophysiological parameters that indicate a prolonged and more heterogeneous repolarization among diabetic patients with uncontrolled $\mathrm{BP}$, is considerable high and seems to be significantly associated with demographic and clinical parameters: gender, BMI, duration of diabetes, duration of BP and glycemic control.

\section{Keywords}

\section{Dispersion of Ventricular Repolarization, Type-2 Diabetes, Arterial Hypertension}

\section{Introduction}

Systematic arterial hypertension and diabetes mellitus type-2, are both common chronic contitions that frequently coexist. Patients with both disorders have a markely higher risk for cardiovascular complication [1]-[4].

Recently, reports of the Joint National Committee on prevention, detection, evaluation and treatment of high blood pressure (JNC 8), European Society of Hypertension (ESH), European Society of Cardiololgy (ESC), concluded that blood pressure measurement in diabetic patients should be less than 140/90 $\mathrm{mmHg}$ [5] [6].

Blood pressure is poorly controlled in most European countries and the control rate is even lower in high-risk patient such as diabetic patients [7]-[10].

In hypertensive patient, the severity of blood pressure and the level of blood pressure control affect the cardiovascular risk significantly. There is evidence that the arrhythmic and sudden cardiac death risk in hypertension increase with rises in blood pressure [4]. Diabetes is associated with greater regional heterogeneity of ventricular repolarization. QT-dispersion that reflects spatial inhomogeneity of ventricular repolarization and Tpeak-Tend dispersion that reflects transmural inhomogeneity of ventricular repolarization, are associated with increased risk of certain arrhythmias and sudden cardiac death in type 2 diabetic patients [11]-[13].

In patients with diabetes mellitus and hypertension, high risk of cardiovascular morbidity and mortality remains elevated even after normalization of conventional cardiovascular risk factors (hypertension, dyslipidemia, physical inactivity, smoking habit, etc.), which suggests the existence of other mechanisms. The ventricular electrical instability, manifested in changes in the QT parameters, appears to be another important mechanism [14]. Interlead variability of the QT interval, on the standard 12 lead- ECG defined as QT dispersion, reflects regional differences in ventricular repolarization. Abnormal QT intervals (both prolonged maximum QT interval and increased QT dispersion) are associated with increased cardiovascular risk [15].

Data relating to the frequency of increased repolarization dispersion, among uncontrolled arterial hypertension in type-2 diabetics patient in western region of the Republic of Macedonia are scarce.

\section{Objectives}

This study, aimed to describe the epidemiology of repolarization dispersion (QT interval, QT dispersion, TpeakTend interval, Tpeak-Tend dispersion) and further describe their associated clinical correlates among uncontrolled arterial hypertension in type-2 Diabetics patient, in western region of the Republic of Macedonia.

\section{Material and Methods}

A total of 600 patients, was enrolled into this observational study.The study was conducted at outpatient in Ptrimary Health Care Clincs in 8 town,on west region Republic of Macedonija. Study participans were selectet among primary care patient, who were receiving ongoing care for diabetes mellitus and hypertension during 1 calendar year (from February 2015 to February 2016).

Inclusion criteria. Patient was eligible for inclusion in the study if they were between 45 and 79 years of age, 
were under treatment for hypertension and diabetes mellitus, diagnosed in accordance with: the Joint National Committee on prevention, detection, evaluation and treatment of high blood pressure(JNC 8) [5] [6], the criteria of the American Diabetes Association [16].

Exclusion criteria included a diagnosis of dementia senilis, secondary hypertension,serum creatinine level $>2$ $\mathrm{mg} / \mathrm{dl}$, age under 45 and over 79. cardiac arrhythmias, congenital or acquired valvular heart disease, left/right bundle branch block, pre-excitation syndromes, patients with pacemakers, and those on hemodialysis and patients treated with drugs that prolong the QT interval, suggested by the ESC [17].

Clinical and Demographic Characteristics: Detailed anamnesis and a complete physical examination of each patient were done.The clinical data included: age, sex, body weight and height, body mass index (BMI), the duration of diabetes and arterial hypertension. The values of glycaemia, serum electrolytes $\left(\mathrm{Na}^{+}, \mathrm{K}^{+}\right)$, serum urea and creatinine were measured in all case and control subjects. Routine biochemical measurements were performed.

Blood Pressure. Measuring of blood pressure according to standard protocol [5] [6]. The mean systolic and diastolic blood pressure, recording during the study period, were calculated. Patient were categorized according to their blood pressure (BP) levels as Group 1-patient with controlled BP $(<140 / 90 \mathrm{mmHg})$ or Group 2-patient with uncontrolled BP $(>140 / 90 \mathrm{mmHg})$.

Electrocardiogram. A simple 12-lead ECG was recorded in all patients. The ECG was always performed with the patients lied down in supine position at rest, at a paper speed of $50 \mathrm{~mm} / \mathrm{s}$ and voltage of $10 \mathrm{~mm} / \mathrm{mV}$. An electrocardiograph Cardio-line - Delta 1 Plus was used for ECG recording. Only patients with normal electrocardiogram were included on the study ECG measurements were performed manually using a digital caliper with measuring range of $0-150 \mathrm{~mm}, 0.01 \mathrm{~mm}$ resolution, and $0-100 \pm 0.02 \mathrm{~mm}$ accuracy. The value obtained was converted to milliseconds (ms). QT interval measurement (the interval from the start of the QRS complex to the end of the T-wave) was performed in all 12 leads, and the longest and the shortest intervals measured were selected. QT interval dispersion was obtained by the difference between the maximum and the minimum QT intervals found in the 12-lead electrocardiogram. The QT interval was corrected according to Bazett's formula that consists in dividing the measured QT by the square root of the RR interval $(\mathrm{QTc}=\mathrm{QT} / \sqrt{\mathrm{RR}})$, thus providing the QT interval value adjusted for heart rate. The QTc dispersion was obtained by the difference between the highest and the lowest values of QTc in the 12 leads of the ECG [18]. According to internationally accepted guidelines, the QTc interval was considered prolonged when greater than $440 \mathrm{~ms}$ for male patients, and greater than $460 \mathrm{~ms}$ for female patients [19]. The QT dispersion was considered prolonged when higher than $65 \mathrm{~ms}$, according to other previously conducted studies [20]. Measurement of the Tpeak-Tend interval was done in standar lead II, and chest V2 and V5 leads. The Tpeak-Tend interval was obtained from the difference between QT interval and QTpeak interval. The Tpeak-Tend interval was considered prolonged when greater than $100 \mathrm{ms,}$ and the Tpeak-Tend dispersion was considered prolonged when greater than $20 \mathrm{~ms}$, as suggested by other studies [21] (Figure 1, Figure 2). The ECG was performed by the same operator, and the aforementioned measurements were made by two independent observers. In case of disagreement on the values obtained, the measurements were repeated by a third observer with expertise in electrocardiographic analysis.

The study is in compliance with the Declaration of Helsinki. All patients that participated in this study were informed in detail and were asked to provide written accordance for their voluntary participation in the study.

\section{Statistical Analysis}

The distribution of variables was tested for normality using the Kolmogorov-Smirnov test, and the heterogeneity of variances was evaluated by Levene's test. A simple descriptive analysis was performed for the general characterization of the sample and distribution of variables. Continuous variables were presented as mean \pm standard deviation, and categorical variables were presented as frequency (\%). Differences between groups were analyzed using the Student $t$ test for independent samples. Categorical data were analyzed using the chi-square $\left(\mathrm{X}^{2}\right)$ test. The logistical regressive analysis is used for testing the association between the categorized variables. A, $p$ value $<0.05$ was considered statistically significant for a confidence interval of $95 \%$. The data are shown in tables and graphics. The collected data were analyzed with SPSS for Windows, version 20.0.

\section{Results}

A total of 600 hypertensive diabetic patients, (49.7\% females and $50.3 \%$ males: mean age $62 \pm 5.8$ years) completed the survey and provided data for a one-year medical record review. A mean of 4.5 blood pressure re- 

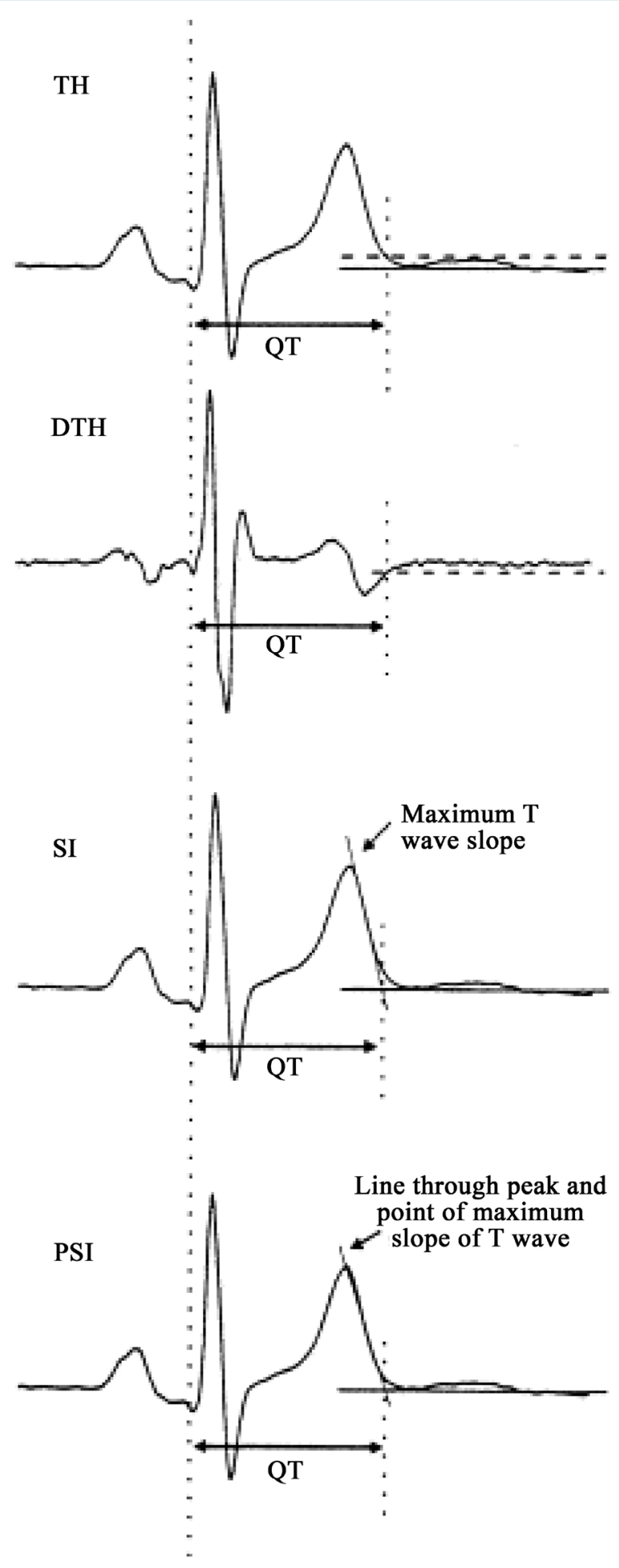

Isoelectric level

- . - . Threshold level

Figure 1. QT measurement. From top to bottom: threshold method applied to the original T wave (TH), or to its differential (DTH), tangent method with a tangent to the steepest point of the descending limb of the T wave (SI), tangent method with a line through the $\mathrm{T}$ wave peak and the maximum slope point (PSI). 
(a) Tp-Te: 120

Tp-e disp: 40 (b) Te-e: 80-

Tp-e disp: 20 (c) Tp-e: 80

Tp-e disp: 20
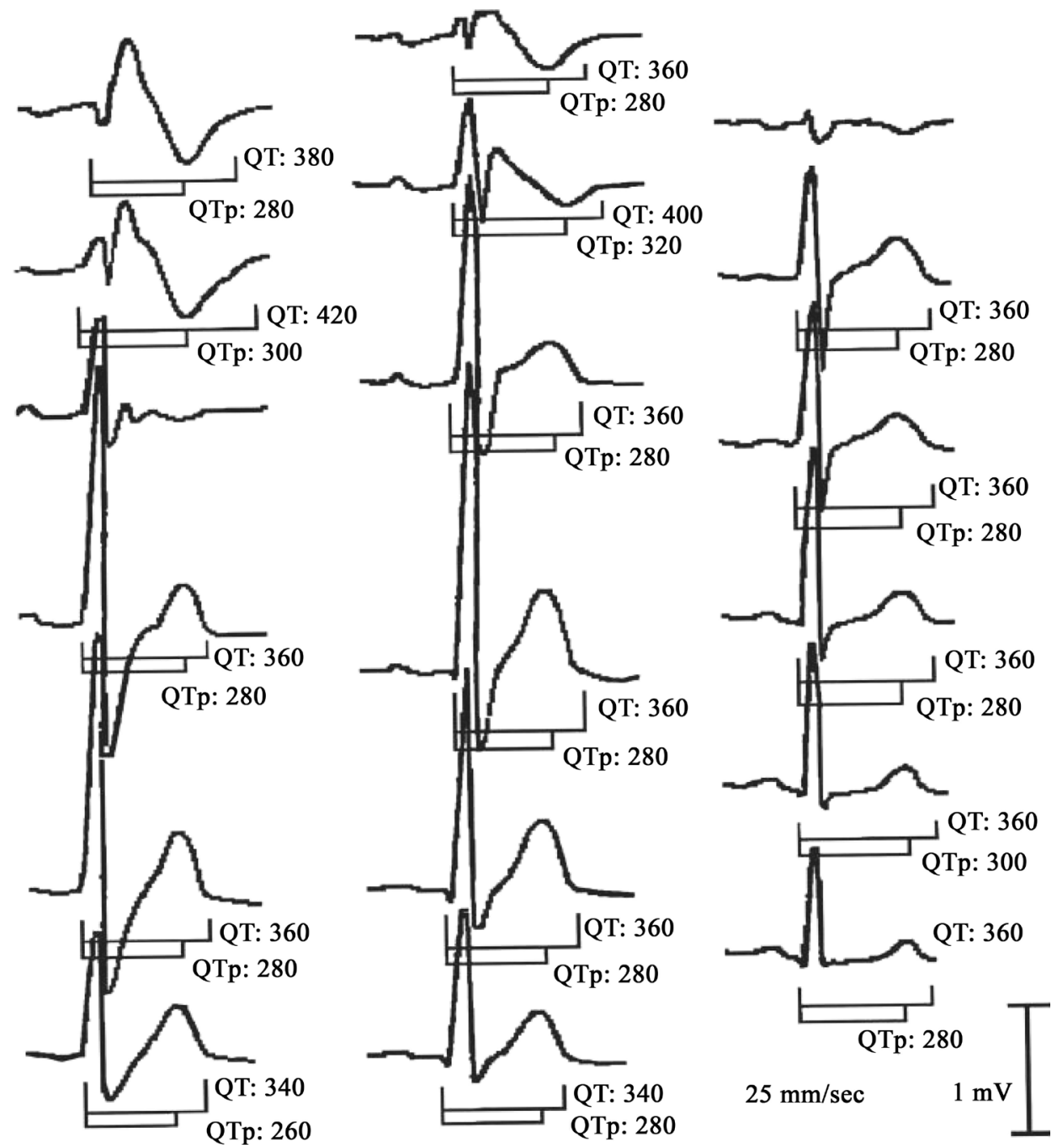

Figure 2. Electrocardiographic (QT, Tp-Te) dispersion measurement examples, from measurements that were taken manually from the tracings at $25 \mathrm{~mm} / \mathrm{sec}$.

cording was obtained for each patient. Table $1 \&$ Table 2 present basic demographic, clinical and laboratory characteristics of studied population.

It was observed that, a small percentage (37.5\%) of hypertensive diabetic patients, had their blood pressure control according to evidence and current guidelines, while a high percentage $(62.5 \%)$ of hypertensive diabetic patients, have uncontrolled their blood pressure, despite ongoing medical treatment.The difference was found to be statistically significant (Chi-square $=26.5 ; \mathrm{p}=0.000$ ). There were statistically significant differences in BMI, between the study group \{(patients with uncontrolled BP) and control group \{(patients with controlled BP), (29.1 \pm 4.5 vs. $27.6 \pm 4.2, \mathrm{p}<0.0009$, respectively) $\}$. Participants with uncontrolled BP had longer duration of arterial hypertension ( $6.5 \pm 1.7$ year vs. $5.9 \pm 1.6$ year, $\mathrm{p}=0.0003$, respectively).

Participants with uncontrolled BP had longer duration of D.M $(5.9 \pm 2.0$ year vs. $5.07 \pm 2.2$ year, $\mathrm{p}=0.0002$, respectively). There were statistically significant differences in glycemic control between the study group and control group $(6.3 \pm 0.6$ vs. $5.9 \pm 0.3 ; \mathrm{p}=0.0000$, respectively). No significant changes were observed in relation to gender, between the study group and control group $(49.7 \%$ females vs. $50.3 \%$ males, $p=0.7$, respectively). There were not statistically significant differences in age, between the study group and control group $(61.5 \pm 5.1$ years vs. $60.6 \pm 5.8$ years, $\mathrm{p}=0.7$, respectively). No significant changes were observed in relation to number of visits 
between the study group and control group (4.4 vs. 4.5. $\mathrm{p}=0.7$, respectively). No significant changes were observed in relation to electrolytes $\left(\mathrm{Na}^{+} 135.2 \pm 4.5\right.$ vs. $136.3 \pm 5.1, \mathrm{p}=0.24 ; \mathrm{K}^{+} 3.9 \pm 0.6$ vs. $3.8 \pm 0.7, \mathrm{p}=0.32$ respectively). No significant changes were observed in relation to serum (urea, creatin) between the study group and control group ( $4.2 \pm 2.2$ vs. $2.1 \pm 1.2, \mathrm{p}=0.31$, respectively; $80.9 \pm 7.5$ vs. $80.4 \pm 6.2, \mathrm{p}=0.7$, respectively).

We conducted a comparative analysis between the study group (patients with uncontrolled BP) and control group (patients with controlled BP), of the following parameters: QT and QTc intervals, QT and QTc dispersions, Tpeak-Tend intervals, and Tpeak-Tend dispersions. Data are shown in Tables 3-6 and Figure $1 \&$ Figure 2).

QT and QTc intervals: The results showed that, the only QTc. max. interval, were significantly greater in study group than in control ( $440.41 \pm 18.2 \mathrm{~ms}$ vs. $437.02 \pm 18.8 \mathrm{~ms}, \mathrm{p}=0.04$, respectively). No significant differences were observed between groups in: others means QT. intervals and means of corrected for Heart rate QT.

Table 1. Basic demographic, clinical and laboratory characteristics of study population $(n=600)$.

\begin{tabular}{ccccc}
\hline Variables & N & Mean & Stand.deviation & $\pm 95 \%$ Confid.interval \\
\hline Age (y) & 600 & 61.05 & \pm 5.8 & $60.5-62.4$ \\
Females (n.\%) & 298 & $49.7 \%$ & & \\
Males (n.\%) & 302 & $50.3 \%$ & & $75.3-77.2$ \\
BW (kg) & 600 & 76.28 & \pm 11.8 & $168.3-169.4$ \\
BH (cm) & 600 & 168.88 & \pm 6.5 & $26.9-27.6$ \\
BMI (kg/m) & 600 & 27.3 & \pm 3.9 & $6.2-6.5$ \\
BP-d (y) & 600 & 6.3 & \pm 1.7 & $5.0-5.3$ \\
DM-d (y) & 600 & 5.2 & \pm 2.0 & $4.3-4.4$ \\
No- of visits. & 600 & 4.4 & \pm 0.6 & $136.1-140.2$ \\
Na ${ }^{+}(\mathrm{mmol} / \mathrm{dl})$ & 600 & 136.2 & \pm 4.6 & $3.9-4.0$ \\
$\mathrm{~K}^{+}(\mathrm{mmol} / \mathrm{dl})$ & 600 & 3.9 & \pm 0.5 & $6.2-7.9$ \\
S.Urea (mmol/dl) & 600 & 6.2 & \pm 2.1 & $80.4-81.6$ \\
\hline S.Creat. (mmol/dl) & 600 & 80.9 & \pm 7.5 & \\
\hline
\end{tabular}

Values are mean $\pm \mathrm{SD} ; \mathrm{y}=$ year; No- of visits = number of measures of BP during 1-year; $\mathrm{BW}=$ body weight; $\mathrm{BH}=$ body height; $\mathrm{BMI}=$ body mass index; BP-d = blood pressure duration; D.M-d = diabetes mellitus duration in years; Glic $=$ glicemia; S.urea $=$ serum urea; S.creat $=$ serum creatinin.electrolites $(\mathrm{Na}, \mathrm{K}$,$) . \mathrm{p}<0.05=$ statistical significance.

Table 2. Basic demographic, clinical and laboratory characteristics of study groups:diabetics with uncontrolled BP (Gr.1; $\mathrm{n}-375)$ and diabetics with controlled BP (Gr.2; n-225).

\begin{tabular}{|c|c|c|c|c|c|}
\hline \multirow{2}{*}{ Variables } & \multicolumn{2}{|c|}{ Gr.1. Uncontrolled B.P. (>140/90mmHg; n-375) } & \multicolumn{2}{|c|}{ Gr.2. Controlled B.P. $(<140 / 90 \mathrm{~mm} . \mathrm{Hg} ;$ n-225) } & \multirow{2}{*}{ P-Value } \\
\hline & Mean;(\%) & S.D. & Mean(\%) & S.D. & \\
\hline Age (year) & 61.5 & \pm 6.1 & 60.6 & \pm 5.2 & 0.7 \\
\hline Females $(\%)$ & 49.1 & & 48.4 & & 0.9 \\
\hline Males (\%) & 50.9 & & 51.6 & & 0.9 \\
\hline BMI $(\mathrm{kg} / \mathrm{m})$ & 29.2 & \pm 4.5 & 27.6 & \pm 4.2 & 0.009 \\
\hline BP $(\%)$ & 62.5 & & $37.5 \%$ & & 0.000 \\
\hline BP-d (year) & 6.5 & \pm 1.7 & 5.9 & \pm 1.6 & 0.003 \\
\hline DM-d (year) & 5.9 & \pm 2.0 & 5.1 & \pm 2.2 & 0.002 \\
\hline Glic. (mmol/dl) & 6.3 & \pm 0.6 & 5.9 & \pm 0.3 & 0.000 \\
\hline $\mathrm{Na}^{+}(\mathrm{mmEq})$ & 136.2 & \pm 4.6 & 135.7 & \pm 3.5 & 0.23 \\
\hline $\mathrm{K}^{+}(\mathrm{mmEq})$ & 3.9 & \pm 0.5 & 3.8 & \pm 0.7 & 0.31 \\
\hline S.Urea $(\mathrm{mmol} / \mathrm{dl})$ & 6.2 & \pm 2.1 & 6.3 & \pm 1.8 & 0.3 \\
\hline S.Creat $(\mathrm{mmol} / \mathrm{dl})$ & 80.9 & \pm 6.5 & 82.5 & \pm 4.6 & 0.2 \\
\hline
\end{tabular}

Values are: \%, $\mathrm{n}$, mean $\pm \mathrm{SD} ; \mathrm{y}=$ year; $\mathrm{BP}$; bloood presure; No- of visits = number of measures of $\mathrm{BP}$ during 1-year; $\mathrm{BW}=$ body weight; $\mathrm{BH}=$ body height; $\mathrm{BMI}=$ body mass index; BP-d = blood pressure duration; D.M-d = diabetes mellitus duration in years; Glic = glicemia; S.urea = serum urea; S.creatin $=$ serum creatinin. Electrolites $(\mathrm{Na}, \mathrm{K},) . \mathrm{p}<0.05$ : staistical significance. 
Table 3. Characteristics of abnormal QT and T wave-intervals in diabetic patients with uncontrolled BP and controlled BP.

\begin{tabular}{|c|c|c|c|c|}
\hline \multicolumn{2}{|c|}{ Electrocardiographic Variables } & $\begin{array}{l}\text { Gr. 1: Uncontrolled B.P. } \\
(>140 / 90 \mathrm{mmHg} ; \mathrm{n}-375)\end{array}$ & $\begin{array}{l}\text { Gr. 2: Controlled B.P. } \\
(<140 / 90 \mathrm{mmHg} ; \mathrm{n}-225)\end{array}$ & p-values \\
\hline \multirow{3}{*}{ QT-interval.(ms) } & QT-max. & $398.28 \pm 12.2$ & $397.36 \pm 12.1$ & 0.75 \\
\hline & QT-mean. & $383.40 \pm 9.4$ & $383.74 \pm 9.8$ & 0.67 \\
\hline & QT-min. & $368.38 \pm 26.4$ & $366.06 \pm 33.2$ & 0.34 \\
\hline \multirow{3}{*}{ QTc-interval.(ms) } & QTc.max. & $440.41 \pm 18.2$ & $437.02 \pm 18.8$ & 0.03 \\
\hline & QTc.mean. & $416.59 \pm 8.8$ & $415.81 \pm 9.6$ & 0.31 \\
\hline & QTc.min. & $383.45 \pm 20.4$ & $382.52 \pm 17.5$ & 0.57 \\
\hline \multicolumn{2}{|c|}{ QT-Dispersion.(ms) } & $27.05 \pm 6.7$ & $26.64 \pm 7.05$ & 0.47 \\
\hline \multicolumn{2}{|c|}{ QTc-Dispersion.(ms) } & $47.61 \pm 18.27$ & $44.98 \pm 18.78$ & 0.000 \\
\hline \multirow{3}{*}{$\begin{array}{c}\mathrm{T}_{\text {Peak }}-\mathrm{T}_{\text {end }}-\text { interval }(\mathrm{ms}) \\
\mathrm{T}_{\text {peak }}-\mathrm{T}_{\text {end }}-\text { iiininterval }(\mathrm{ms}) \\
\text { Intervals }(\mathrm{ms})\end{array}$} & Lead II & $70.68 \pm 6.1$ & $70.13 \pm 7.1$ & 0.33 \\
\hline & Lead $V_{2}$ & $71.28 \pm 4.1$ & $71.10 \pm 4.7$ & 0.61 \\
\hline & Lead $\mathrm{V}_{5}$ & $81.55 \pm 2.44$ & $79.94 \pm 8.07$ & 0.13 \\
\hline \multicolumn{2}{|c|}{$\mathrm{T}_{\text {peak }}-\mathrm{T}_{\text {end }}-\mathrm{Dispersion}(\mathrm{ms})$} & $21.3 \pm 7.7$ & $12.1 \pm 7.0$ & 0.000 \\
\hline
\end{tabular}

QTc-max-QTc-maximal duration in ms; QT-min: minimal duration; QTc-dispers- QTc-dispersion in miliseconds; Tp-Te = duration of Tpeak-Tend interval in miliseconds; TpTe dispersion $=$ duration of Tpeak-Tend dispersion in milliseconds. P-value $<0.05$ staistical significance.

Table 4. Frequency of observed characteristics of abnormal QT and T wave-intervals in diabetic patients with uncontrolled $\mathrm{BP}$ and controlled BP.

\begin{tabular}{ccccc}
\hline Electrocardiographic Variables & $\begin{array}{c}\text { Gr. 1: Uncontrolled B.P. } \\
\mathbf{( > 1 4 0 / 9 0 m m H g ; ~ n - 3 7 5 )} .\end{array}$ & $\begin{array}{c}\text { Gr. 2: Controlled B.P. } \\
(<\mathbf{1 4 0 / 9 0 m m H g , ~ n - 2 2 5 )} .\end{array}$ & Tot.(n-600) & p-level \\
\hline Prolongation of QTc-max.-interval (n;\%). & $138(61.4 \%)$ & $76(33.6 \%)$ & $214(35.6)$ & $\mathbf{0 . 0 0 5}$ \\
Increased dispersion of QTc-inerval (n;\%). & $155(65.9 \%)$ & $80(34.1 \%)$ & $235(39.1)$ & $\mathbf{0 . 0 0 0 1}$ \\
Prolongation of Tp-Te.interval (n;\%). & $81(65.3 \%)$ & $43(34.7 \%)$ & $124(20.6)$ & $\mathbf{0 . 0 0 5}$ \\
Increased dispersion of Tp-Te-interval (n;\%). & $95(65.5 \%)$ & $50(24 \%)$ & $145(24.1)$ & $\mathbf{0 . 0 0 2}$ \\
\hline
\end{tabular}

QTc-max-QTc-maximal duration in ms; QTc-dispers- duration of QTc-dispersion in ms; Tp-Te = duration of Tpeak- $\mathrm{T}$ end interval in ms; TpTe dispersion $=$ duration of Tpeak-Tend dispersion in ms. F-females; M-males; P-value $<0.05$ staistical significancy.

Table 5. Clinical correlates of increased dispersion of QTc. interval.

\begin{tabular}{|c|c|c|c|c|c|c|c|c|}
\hline \multirow{2}{*}{ Explanatory variables ${ }^{\mathrm{a}}$} & \multirow{2}{*}{$\mathrm{B}$} & \multirow{2}{*}{ S.E. } & \multirow{2}{*}{ Wald } & \multirow{2}{*}{$\mathrm{df}$} & \multirow{2}{*}{ Sig. } & \multirow{2}{*}{$\operatorname{Exp}(B)$} & \multicolumn{2}{|c|}{ 95\%C.I. $\operatorname{Exp(B)}$} \\
\hline & & & & & & & Lower & Upper \\
\hline Uncontrolled high BP & 0.127 & 0.174 & 0.533 & 1 & 0.046 & 1.136 & 0.807 & 1.598 \\
\hline BMI & 1.706 & 0.183 & 87.292 & 1 & 0.000 & 5.504 & 3.849 & 7.872 \\
\hline High BP duration & 0.501 & 0.060 & 70.387 & 1 & 0.000 & 1.037 & 1.468 & 1.850 \\
\hline DM duration & 0.577 & 0.55 & 111.720 & 1 & 0.000 & 1.781 & 1.600 & 1.982 \\
\hline Female gender & 0.747 & 0.171 & 19.121 & 1 & 0.000 & 2.11 & 1.510 & 2.950 \\
\hline Uncontrolled hyperglycemia & 0.777 & 0.171 & 20.612 & 1 & 0.000 & 2.176 & 1.556 & 3.004 \\
\hline
\end{tabular}

${ }^{\mathrm{a}}$ Variable (s) entered on step 1: Uncontrolled blood pressure; $\mathrm{BMI}=$ body mass index; Dur of BP = duration of blood presure; D ur.of D.M. = duration of Diabetes Melitus(year); (f)Gender = Females; Unc.glic = uncontrolled glicemia.

Table 6. Clinical correlates of increased dispersion of Tpeak-Tend interval.

\begin{tabular}{|c|c|c|c|c|c|c|c|c|}
\hline \multirow{2}{*}{ Explanatory variables ${ }^{\mathrm{a}}$} & \multirow{2}{*}{$\mathrm{B}$} & \multirow{2}{*}{ S.E. } & \multirow{2}{*}{ Wald } & \multirow{2}{*}{ df } & \multirow{2}{*}{ Sig. } & \multirow{2}{*}{$\operatorname{Exp}(B)$} & \multicolumn{2}{|c|}{ 95\% C.I. EXP(B) } \\
\hline & & & & & & & Lower & Upper \\
\hline Female gender & 0.756 & 0.199 & 14.461 & 1 & 0.000 & 2.130 & 1.442 & 3.114 \\
\hline BMI & 0.376 & 0.194 & 3.746 & 1 & 0.043 & 1.456 & 0.995 & 2.30 \\
\hline DM duration & 0.111 & 0.045 & 6.048 & 1 & 0.040 & 1.117 & 1.023 & 1.220 \\
\hline Uncontrolled glycemia & 0.880 & 0.196 & 18.387 & 1 & 0.000 & 2.317 & 1.578 & 3.401 \\
\hline
\end{tabular}

${ }^{\mathrm{a}}$ Variable (s) entered on step 1: Uncontrolled blood pressure; BMI = body mass index; Dur of BP = duration of blood presure; D ur.of D.M. = duration of Diabetes Melitus (year); (F) Gender = Females; Unc.glic = uncontrolled glicemia. 
intervals. QT max. $(397.36 \pm 12.15$ ms. vs. $396.11 \pm 12.28$ ms. p=0.94); QTmin. $(368.39 \pm 26.4$ ms. vs. $366 \pm$ $33.18 \mathrm{~ms} . \mathrm{p}=0.34)$; QTmean. (383 $\pm 74 \mathrm{~ms}$. vs. $383 \pm 40 \mathrm{~ms}, \mathrm{p}=0.67)$; QTc.min. $(383.45 \pm 20.41 \mathrm{~ms}$. vs. $382.52 \pm 52 \mathrm{p}=0.57)$; QTc.mean (416.59 $\pm 8.8 \mathrm{~ms}$. vs. $415.71 \pm 9.6 \mathrm{~ms}, \mathrm{p}=0.31$, respectively). A prolonged QTC.max.interval: was found in $37.5 \%$ of total hypertensive diabetic patients. Patients with uncontrolled BP, have a significantly greater prolonged mean QTc.max.interval (61.3\% vs. 33.6\%) than patients with controlled BP. The differences were statistically significant (Chi-square: $12.30 ; \mathrm{p}=0.0005$, respectively).

Dispersion of QT and QTc intervals: The results showed that patients with uncontrolled BP, have a significantly greater mean dispersion of QTc.interval, than patients with controlled BP, $(47.61 \pm 18.27 \mathrm{~ms}$ vs. $40.68 \pm 21.36$ $\mathrm{ms}, \mathrm{p}=0.007)$. No significant differences were observed between groups in mean dispersion of QT. interval. ( $27.05 \pm 6.6 \mathrm{~ms}$ vs. $26.64 \pm 7.0 \mathrm{~ms}, \mathrm{p}=0.47$, respectively).

A prolonged mean dispersion of QTc.interval, was found in $39.1 \%$ of total hypertensive diabetic patients. Patients with uncontrolled BP, have a significantly greater prolonged mean dispersion of QTc.interval $(65.9 \%$ vs. $34.1 \%$ ) than patients with controlled BP.The differences were statistically significant (Chi-square: $16.14 ; \mathrm{p}=$ 0.0001 , respectively). There was observed greater frequency of prolonged dispersion of QTc.interval in females than males with uncontrolled BP $(61.2 \%$ vs. $38.7 \%$; Chi-square: $5.30 ; \mathrm{p}=0.02)$.

Tpeak-Tend intervals: Regarding the comparison of Tpeak-Tend intervals, were no statistically significant differences in any of the comparisons made between study and control group. The mean Tpeak-Tend-intervals in: DII (70.68 $\pm 6.06 \mathrm{~ms}$ vs. $70.13 \pm 7.11 \mathrm{~ms}, \mathrm{p}=0.33$; V2 $(71.28 \pm 4.17 \mathrm{~ms}$ vs. $71.10 \pm 4.15 \mathrm{~ms}, \mathrm{p}=0.61$; V5 $(81.55 \pm 13.48 \mathrm{~ms}$ vs. $79.94 \pm 12.29 \mathrm{~ms}, \mathrm{p}=0.13$, respectively).

Comparing the frequency of subjects with a prolonged Tpeak-Tend interval: (above the cut-off limit determined for the study) prolonged Tpeak-Tend interval was found in $39.1 \%$ of total hypertensive diabetic patients. Patients with uncontrolled BP, have a significantly greater frequency of prolonged mean Tpeak-Tend interval $(65.3 \%$ vs. $34.7 \%)$ than patients with controlled BP. The differences were statistically significant (Chi-square: $7.85 ; \mathrm{p}=0.005$, respectively). There was observed greater frequency of prolonged Tpeak-Tend interval in females than males with uncontrolled BP (40.3\% vs. 20.2\%; Chi-square: $5.76 ; \mathrm{p}=0.01)$.

Dispersion of Tpeak-Tend interval: Regarding the comparison of Dispersion of Tpeak-Tend intervals, in group with uncontrolled BP and group with controlled BP, the results showed that patients in group with uncontrolled BP have a significant greater mean dispersion of Tpeak-Tend interval than patients in group with controlled BP $(21.3 \pm 7.7 \mathrm{~ms}$ vs. $12.1 \pm 7.0, \mathrm{p}=0.000)$.

Comparing the frequency of subjects with a prolonged Dispersion of Tpeak-Tend interval: (above the cut-off limit determined for the study), prolonged dispersion of Tpeak-Tend interval was found in $24.1 \%$ of total hypertensive diabetic patients.Patients with uncontrolled BP, have a significantly greater frequency of prolonged mean dispersion of Tpeak-Tend interval (65.5\% vs. 34.5\%) than patients with controlled BP. The differences were statistically significant (Chi-square: $9.41 ; \mathrm{p}=0.002$, respectively). There was observed greater frequency of prolonged dispersion of Tpeak-Tend interval in females than males with uncontrolled BP (Chi-square: 6.86 ; $p$ $=0.008)$.

Fitting logistic regression models including all study participants without missing values $(\mathrm{N}=600)$, we found that: prolonged QTc.max. was associated with: uncontrolled BP (OR-1.345, 95\%C.I. 0.951 - 1.09). Prolonged dispersion of QTc. interval was associated with: uncontrolled B.P. (OR = 1.136, 95\%C.I 0.807 - 1.598), BMI $(\mathrm{OR}=5.504,95 \%$ C.I. $3.849-7.872)$, duration of arterial hypertension $(\mathrm{OR}=1.650,95 \%$ C.I. $1.468-1.850)$, duration of D.M $(\mathrm{OR}=1.781$, 95\%C.I. 1.600 - 1.982), gender $(\mathrm{OR}=2.11$, 95\%C.I. 1.510 - 2.950), uncontrolled glycemia, $(\mathrm{OR}=2.176,95 \%$ C.I 1.556 - 3.044). Prolonged dispersion of Tpeak-Tend interval was associated with: BMI (OR = 1.456, 95\%CI. 0.995 - 2.130), duration of B.P. (OR = 1.037, 95\%CI. 0.929 - 1.157), duration of D.M. $(\mathrm{OR}=1.117,95 \%$ C.I. 1.023 - 1.220), uncontrolled glycemia $(\mathrm{OR}=2.317,95 \%$ CI. 1.578 - 3.401$)$.

\section{Discussion}

The QT interval is the most used parameter in the electrocardiographic assessment of repolarization and its prolongation is associated with increased risk of arrhythmogenesis [22]-[25]. Literature data report a higher incidence of ventricular arrhythmias in hypertensive versus normotensive patients. In the present study, we provide evidence that a significant proportion of hypertensive diabetic patients in Western Region of the Republic of Macedonia, are already at increased cardiovascular risk considering the fact that uncontrolled BP and abnormal QT interval ( prolonged maximum QTc interval, increased QTc dispersion, prolonged Tp-Te 
interval and increased Tp-Te dispersion), are associated with increased cardiovascular risk [25]-[28]. In the present study, a small percentage (37.5\%) of hypertensive diabetic patients, had their blood pressure control according to evidence and current guidelines [5] [6], while a high percentage (62.5\%) of hypertensive diabetic patients, have uncontrolled their blood pressure, despite ongoing medical treatment. This indicated that more effort is needed to control blood pressure in diabetics. When comparing the QT intervals between group with uncontrolled BP and group with controlled BP, no significant differences were found; however, the QT interval does not take into account the heart rate and, therefore, these results had no clinical relevance. However, after correcting the QT interval for heart rate using the formula of Bazzet, we found significant differences between group with uncontrolled BP and group with controlled BP.The prevalence of prolonged QTc max.interval in the present study was $37.5 \%$. Over $61 \%$ of diabetics with uncontrolled BP had prolonged QTc max.interval. This is similar to the report of other studies [28]-[31]. In our study, significant differences between groups, were observed in prevalence of prolonged dispersion of QTc interval. The prevalence of prolonged dispersion of QTc interval in the present study was $39.1 \%$. Over $65.9 \%$ of diabetics with uncontrolled BP, had prolonged dispersion of QTc interval, indicating that the repolarization in diabetics with uncontrolled BP was more heterogeneous than that observed in diabetics with controlled BP.Several studies have associated this, to an increasing ventricular inhomogeneity of the myocardium and associated predisposition to cardiac arrhythmias [32]. Prolonged QTc max.interval and increased dispersion of QTc.interval, have been observed to be good predictors of arrhythmia and sudden cardiac death in such conditions as long QT syndrome, hypertrophic cardiomyopathy, hypertension, chronic heart failure, post myocardial infarction patients, and in diabetes mellitus patients [33] [34]. Diabetics with uncontrolled BP, prolonged QTc interval and prolonged dispersion of QTc.interval, are therefore at an increased cardiovascular risk compared to diabetics with controlled BP, normal QTc intervals and normal dispersion of QTc.interval [35] [36]. It is known a potential role of ECG indices,the Tpeak-Tend interval, is a parameter that reflects the transmural repolarization heterogeneity and has been associated with increased risk of mortality not oly in high-risk patient but also in general population [37]. In this study,when comparing the Tpeak-Tend intervals between group with uncontrolled BP and group with controlled BP, no significant differences were found. One of thereasons for these results may have been the use of only three leads (DII, V2 and V5), which although providing a substantially orthogonal assessment (XYZ). In the present study, significant differences were observed in prevalence of prolonged value of Tpeak-Tend dispersion, in diabetics with uncontrolled BP when compared with diabetics with controlled BP. Results that are similar to previous studies of Tpeak-Tend dispersions in hypertensive, diabetic patients [31] [38] [39]. The majority of previous studies have shown that gender demonstrate a complex interaction on indices of myocardial repolarization with different measures behaving differently [40] [41]. In the present study, significant gender differences were observed in prevalence of prolonged values Tpeak-Tend interval, QTc dispersion, Tpeak-Tend dispersion. Others have found similar results [40] [42]. Obesity and BMI have been found to be a strong predictor of sudden cardiac death (SCD) in the Framingham heart study. It has been suggested that sudden deaths and/or ventricular arrhythmias may be linked to abnormalities in ventricular repolarization, maybe associated with early electrocardiographic abnormalities even in the absence of clinical symptoms [43] [44]. In the present study, diabetic patients in group with uncontrolled BP, have a significantly higher BMI. Others have found similar results [29] [35], which led as to conclude that obesity and BMI had significant influence on the various repolarization parameters evaluated. Electrical repolarization abnormalities, have been shown to be associated with duration of DM and BP. In the present study, diabetic patients in group with uncontrolled BP, have a significantly longer duration of diseases (DM and BP). Others have found similar results [31] [35] [45]. Poor glycemic control, have been found to be associated with electrical repolarization abnormalities. In the present study, diabetic patients in group with uncontrolled BP, have a significantly poor glycemic control. This result is in accordance with results of others studies [46]. Another fact of great importance is the influence of medication on several electrocardiographic parameters, because there are numerous drugs that cause prolongation and/or dispersion of repolarization. This study excluded individuals receiving medications that are more frequently associated with repolarization changes; however, there was no absolute guarantee that all other medications had no influence on repolarization. In fact, a study by Costa et al. [47] evaluated the influence of metformin (a drug commonly used in diabetics to control blood glucose) on QT interval and QT dispersion in diabetic rats. The results showed that, with low and moderate doses of metformin, there were significant changes in electrocardiographic parameters, but this did not happen when the dose was high. Treatment with drugs such B-blockers, antidepressant and cisapride may cause QTc prolongation: in this study, theproportion of patients treated with these drugs, was relatively small and the 
exclusion of this subgroup from the analysis, did not modify the relationship between prolonged QTc and diabetics patients. The consistency in the frequency of QTed and prolonged QTc max suggests that there is a relationship between prolonged QTc max and increased QTed in this study as both were well correlated to similar clinical and demographic factors.

This study corroborates similar conclusions by other authors that, hypertensive subjects in developing nations (like Republic of Macedonia) are already more likely to have more target organ damage and excessive cardiovascular morbidity [26] [27] [48].

This study was not without limitations. A larger sample would certainly increase the statistical power of the study, and probably some differences would therefore become more expressive.Moreover, manual measurements of intervals without the support of any technology that could ensure a more precise measurement may also be an aspect to be taken into account. The accuracy and reproducibility of measurements of repolarization parameters problem encountered was the lack of a consensus on the values of several normal electrocardiographic parameters.

Despite some methodological limitations,this study clearly demonstrated a relationship between uncontrolled BP and changes in a set of electrophysiological parameters that indicate a prolonged and more heterogeneous repolarization in these patients, when compared with diabetics patients with controlled BP.

\section{Conclusion}

Frequency of increased set of electrophysiological parameters that indicate a prolonged and more heterogeneous repolarization among diabetic patients with uncontrolled BP, in western region of the Republic of Macedonia is considerable high and seems to be significantly associated with demographic and clinical parameters: gender, BMI, duration of diabetes, duration of BP and glycemic control. These findings have both epidemiological and clinical relevance. This fact may be involved in the greater vulnerability of these patients to cardiac arrhythmias, and excess mortality risk of type 2 diabetic patients with uncontrolled BP. More efforts should be addressed to control the BP in diabetics. Therefore, the assessment of these markers for arrhythmogenic risk may be important for better risk stratification of hypertensive diabetic patients, a conclusion that needs confirmation in larger prospective studies.

\section{References}

[1] Sowers, J.R., Epstein, M., Frohlich, E.D., et al. (2001) Diabetes, Hypertension, and Cardiovascular Disease: An Update. Hypertension, 37, 53-59.

[2] Sowers, J.R. and Haffner, S. (2002) Threatment of Cardiovascular and Renal Risk Factors in Diabetic Hypertensive. Hypertension, 40, 781-788. http://dx.doi.org/10.1161/01.HYP.0000042097.39655.B7

[3] Bakris, G., Williams, M., Dworkin, L., et al. (2000) Preserving Renal Fumgtion in Adult with Hyprtension and Diabetes: A Consensus Approach. Journal of Kidnay Disease, 36, 646.

[4] Yildirir, A., Batur, M. and Oto, A. (2002) Hypertension and Arrhythmia: Blood Pressure Control and Beyond. Europace, 4, 175-182. http://dx.doi.org/10.1053/eupc.2002.0227

[5] James, P.A., Oparil, S., Carter, B.L., et al. (2014) Evidence-Based Guideline for the Management of High Blood Pressure in Adults: Report from the Panel Members Appointed to the Eighth Joint National Committee (JNC 8). JAMA. http://dx.doi.org/10.1001/jama.2013.284427

[6] Mancia, G., Fagard, R., Narkiewicz, K., et al. (2013) ESH-ESC Guidelines for Management of Hypertension. European Heart Journal, 34, 2159-2219.

[7] Gauglas, J.D., Ferdinad, K.C., Bacris, G.L., et al. (2002) Bariers to Blood Pressure Control in African American. Overcaming Obstacles Is Challenging, but Target Goal Can Be Attained. Postgraduate Medicine, 112, 51-62.

[8] Hart, P.D. and Bakris, G.L. (2004) Hyprtension Control Rates:Time Forn Translation of Guidelines into Clinical Practise. American Journal of Medicine, 117, 62-64. http://dx.doi.org/10.1016/j.amjmed.2004.04.003

[9] Gaede, P., Vedel, P., Larsen, N., et al. (2003) Multifactorial Intervention and Cardiovaskular Disease in Patient with Type 2 Diabetes. The New England Journal of Medicine, 348, 338-393. http://dx.doi.org/10.1056/NEJMoa021778

[10] Jani, Y., Kamberi, A., Ferati, F., et al. (2014) Influence of Dyslipidemia in Control of Arterial Hypertension among Type-2 Diabetics in Western Region of Republic of Macedonia. American Journal of Cardiovascular Disease, 4, 5869.

[11] Okin, P.M., Devereux, R.B., Howard, B.V., Fabsitz, R.R., Lee, E.T. and Welty, T.K. (2000) Assessment of QT Interval and QT Dispersion for Prediction of All-Cause and Cardiovascular Mortality in American Indians: The Strong Heart 
Study. Circulation, 101, 61-66. http://dx.doi.org/10.1161/01.CIR.101.1.61

[12] Cardoso, C.R., Salles, G.F. and Deccache, W. (2003) Prognostic Value of QT Interval Parameters in Type 2 Diabetes Mellitus: Results of a Long-Term Follow-Up Prospective Study. Journal of Diabetes and Its Complications, 17, 169 178. http://dx.doi.org/10.1016/S1056-8727(02)00206-4

[13] Veglio, M., Chinaglia, A. and Cavallo-Perin, P. (2004) QT Interval, Cardiovascular Risk Factors and Risk of Death in Diabetes. Journal of Endocrinological Investigation, 27, 175-181. http://dx.doi.org/10.1007/BF03346265

[14] Kumar, R., Fisher, M. and Macfarlane, P.W. (2004) Diabetes and QT Interval: Time for Debate. British Journal of Diabetes \& Vascular Disease, 4, 146-149. http://dx.doi.org/10.1177/14746514040040030201

[15] Day, C.P., McComb, J.M. and Campbell, R.W. (1990) QT Dispersion: An Indication of Arrhythmia Risk in Patients with Long QT Intervals. British Heart Journal, 63, 342. http://dx.doi.org/10.1136/hrt.63.6.342

[16] American Diabetes Association (2002) Standards for Medical Care for Patients with Diabetes Mellitus. Diabetes Care, 25, 213-229. http://dx.doi.org/10.2337/diacare.25.1.213

[17] Haverkamp, W., Breithardt, G., Camm, A.J., Janse, M.J., Rosen, M.R., Antzelevitch, C., et al. (2000) The Potential for QT Prolongation and Proarrhythmia by Non-Antiarrhythmic Drugs: Clinical and Regulatory Implications. Report on a Policy Conference of the European Society of Cardiology. European Heart Journal, 21, 1216-1231. http://dx.doi.org/10.1053/euhj.2000.2249

[18] Chiladakis, J., Kalogeropoulos, A., Arvanitis, P., Koutsogiannis, N., Zagli, F. and Alexopoulos, D. (2009) Heart Rate-Dependence of QTc Intervals Assessed by Different Correction Methods in Patientss with Normal or Prolonged Repolarization. Pacing and Clinical Electrophysiology, 33, 553-560. http://dx.doi.org/10.1111/j.1540-8159.2009.02657.x

[19] Corrado, D., Pelliccia, A., Bjornstad, H.H., Vanhees, L., Biffi, A., Borjesson, M., et al. (2005) Cardiovascular PreParticipation Screening of Young Competitive Athletes for Prevention of Sudden Death: Proposal for a Common European Protocol (Consensus Statement of the Study Group of Sport Cardiology of the Working Group of Cardiac Rehabilitation and Exercise Physiology and the Working Group of Myocardial and Pericardial Diseases of the European Society of Cardiology). European Heart Journal, 26, 516-524. http://dx.doi.org/10.1093/eurheartj/ehi108

[20] Rautaharju, P.M., Suravicz, B., Gettes, L.S., Balley, J.J., Childers, R., Deal, B.J., et al.(2009) AHA/ACCF/HRS Recomandation for the Standartization and Interpretation of the Electrocardiogram: Part IV: The ST Segment, T and U Vaves, and the QT Interval: A Scientific Statement from AHA/ACCF/HRS; the American College of Cardilology Foundation; and the Heart Rhythem Society, Endorsed by International Society for Computeraized Electrocardiology. Journal of the American College of Cardiology, 53, 982-991.

[21] Castro, H.J., Antzelevitch, C., Tornes, B.F., Dorantes, S.M., Dorticos, B.F. and Zayas, M.R. (2006) Tpeak-Tend and Tpeak-Tend Dispersion as Risk Factors for Ventricular Tachycardia/Ventricular Fibrillation in Patients with the Brugada Syndrome. Journal of the American College of Cardiology, 47, 1828-1834. http://dx.doi.org/10.1016/j.jacc.2005.12.049

[22] Xue, J., Gao, W., Chen, Y. and Han, X. (2008) Study of Repolarization Heterogeneity and Electrocardiographic Morphology with a Modeling Approach. Journal of Electrocardiology, 41, 581-587. http://dx.doi.org/10.1016/j.jelectrocard.2008.07.027

[23] Algra, A., Tijssen, J.G.P., Roelandt, J.R.T.C., Pool, J. and Lubsen. J. (1991) QTc Prolongation Measured by Standard 12-Lead Electrocardiography Is an Independent Risk Factor for Sudden Death Due to Cardiac Arrest. Circulation, 83, 1888-1894. http://dx.doi.org/10.1161/01.CIR.83.6.1888

[24] Priori, S.G., Aliot, E., Blomstrom-Lundqvist, C., et al. (2001) Task Force on Sudden Cardiac Death of the European Society of Cardiology. European Heart Journal, 22, 1374-1450. http://dx.doi.org/10.1053/euhj.2001.2824

[25] Mehdi, N., Patric, B., Barbara, S., Bemhard, B., Ruben, C., Danilo, R., et al. (2013) A Novel Electrocardiographic Index for Diagnosis of Diastolic Dysfunction. PLOS ONE, 8, e79152.

[26] Sani, I.M., Solomon, D.S., Imhogene, O.A., Ahmad, A.M. and Bala, G.S. (2006) QT Dispersion in Adult Hypertensives. Journal of the National Medical Association, 98, 631-636.

[27] Clarkson, P.B., Naas, A.A., McMahon, A., MacLeod, C., Struthers, A.D. and MacDonald, T.M. (1995) QT Dispersion in Essential Hypertension. QJM, 88, 327-332.

[28] Festa, A., D’Agostino Jr., R., Rautaharju, P., O’Leary, D.H., Rewers, M., et al. (1999) Is QT Interval a Marker of Subclinical Atherosclerosis in Nondiabetic Subjects? Stroke, 30, 1566-1571. http://dx.doi.org/10.1161/01.STR.30.8.1566

[29] Gryglewska, B., Grodzicki, T., Czarnecka, D. and Kocemba, J. (2000) QT Dispersion and Hypertensive Heart Disease in Elderly. Journal of Hypertension, 18, 461-466. http://dx.doi.org/10.1097/00004872-200018040-00016

[30] Haider, A.W., Larson, M.G., Benjamin, E.J. and Levy, D. (1998) Increased Left Ventricular Mass and Hypertrophy Are Associated with Increased Risk for Sudden Death. Journal of the American College of Cardiology, 32, 1454-1459. http://dx.doi.org/10.1016/S0735-1097(98)00407-0 
[31] Jani, Y., Kamberi, A., Xhunga, S., Pocesta, B., Rexhepi, A., Ferati, F., et al. (2015) The Influence of Type 2 Diabetes and Gender on Ventricular Repolarization Dispersion in Patients with Sub-Clinic Left Ventricular Diastolic Dysfunction. American Journal of Cardiovascular Disease, 5, 155-166.

[32] Robbins, J., Nelson, J.C., Rahtaharju, P.M. and Gottdiener, J.S. (2003) The Association between the Length of the QT Interval and Mortality in the Cardiovascular Health Study. The American Journal of Medicine, 115, 689-694. http://dx.doi.org/10.1016/j.amjmed.2003.07.014

[33] Saadeh, A., Evan, S., James, M. and Jones, J. (1999) QTc Dispersion and Complex Ventricular Arrhythmias in Untreated Newly Presenting Hypertensive Patients. Journal of Human Hypertension, 13, 665-669. http://dx.doi.org/10.1038/sj.jhh.1000908

[34] Zhang, Y., Post, W.S., Blasco-Colmenares, E., Dalal, D., Tomaselli, G.F. and Guallar, E. (2011) Electrocardiografic QT Interval and Mortality: A Meta-Analysis. Epidemiology, 22, 660-670.

[35] Salles, G.F., Deccache, W. and Cardoso, C.R. (2005) Usefulness of QT-Interval Parameters for Cardiovascular Risk Stratification in Type 2 Diabetic Patientss with Arterial Hypertension. Journal of Human Hypertension, 19, 241-249.

[36] Glunti, S., Gruden, G., Fornengo, P., Barutta, F., Amione, C., Gdiovascular Hezzo, G., et al. (2012) Increased QT Interval Dispersion Predict 15-Year Cardiovascular Mortality in Type 2 Diabetic Subjects: The Population-Based Casale Monferrato Study. Diabetes Care, 35, 581-583.

[37] Barbhaiya, C., Po, J.R., Hanon, S. and Schweitzer, P. (2013) $T_{\text {peak }}-T_{\text {end }}$ and $T_{\text {peak }}-T_{\text {end }} / Q T$ Ration as Marker of Ventricular Arrhythmia Risk in Cardiac Resynchronization Therapy Patients. Pacing and Clinical Electrophysiology, 36, 103-108. http://dx.doi.org/10.1111/pace.12031

[38] Castro-Torres, Y., Carmona-Puerta, R. and Katholi, R.E. (2015) Ventricular Repolarization Markers for Predicting Malignant Arrhythmias in Clinical Practice. World Journal of Clinical Cases, 3, 705-720. http://dx.doi.org/10.12998/wjcc.v3.i8.705

[39] Miki, T., Tobisawa, T., Sato, T., Tanno, M., Yano, T. and Akasaka, H. (2014) Does Glycemic Control Reverse Dispersion of Ventricular Repolarization in Type 2 Diabetes? Cardiovascular Diabetology, 13, 125.

[40] Kassotis, J., Costeas, C., Bedi, A.K., Tolat, X. and Reiffel, J. (2000) Effects of Aging and Gender on QT Dispersion in an Overtly Healthy Population. Pacing and Clinical Electrophysiology, 23, 1121-1126. http://dx.doi.org/10.1111/j.1540-8159.2000.tb00912.x

[41] Dos Santos, R.L., da Silva, F.B., Ribeiro Jr., R.F. and Stefanon, I. (2014) Sex Hormones in the Cardiovascular System. Hormone Molecular Biology and Clinical Investigation, 18, 89-103. http://dx.doi.org/10.1515/hmbci-2013-0048

[42] Kohno, I. (1998) QT Dispersion in Dipper- and Nondipper-Type Hypertension. American Journal of Hypertension, 11, 280-285. http://dx.doi.org/10.1016/S0895-7061(97)00474-3

[43] Hubert, H.B., Feinleib, M., McNamara, P.M. and Castelli, W.P. (1983) Obesity as an Independent Risk Factor for Cardiovascular Disease: A 26-Year Follow-Up of Participants in the Framingham Heart Study. Circulation, 67, 968977. http://dx.doi.org/10.1161/01.CIR.67.5.968

[44] Yeung, C.I., Lam, C.S., Li, S.W., Lam, K.F., Tse, H.F. and Siu, C.W. (2012) Sudden Cardiac Death after Myocardial Infarction in Type 2 Diabetic Patients with No Residual Myocardial Ischemia. Diabetes Care, 35, 2564-2569.

[45] David, C., Telmo, P. and Susana, R. (2012) Ventricular Repolarization in Diabetic Patients: Characterization and Clinical Implication. Arquivos Brasileiros de Cardiologia, 99, 1015-1022.

[46] Suis, B., Heuten, S., De Wolf, D., Verherstraeten, M., de Beeck, L.O. and Mathys, D. (2006) Glycemia and Corrected QT Interval Prolongation in Young Type 1 Diabetic Patients: What Is the Relation? Diabetes Care, 29, 427-429.

[47] Costa, E.C., Goncalves, A.A., Areas, M.A. and Morgabel, R.G. (2008) Effects of Metformin on QT and QTc Interval Dispersion of Diabetic Rats. Arquivos Brasileiros de Cardiologia, 90, 232-238. http://dx.doi.org/10.1590/S0066-782X2008000400004

[48] Peng, S., Yu, V., Han, K., Xing, H., Li, D., Chen, C., et al. (2006) Heart Rate Corrected QT Interval Duration Is Significantly Associated with Blood Pressure in Chinese Population. Journal of Electrocardiology, 39, 206-210. http://dx.doi.org/10.1016/j.jelectrocard.2005.08.007 


\section{Abbreviations}

AGE: Age

BMI: Body mass index

BP: Blood pressure

JNC 8: Joint National Committee

ESH: European Society of Hypertension

ESC: European Society of Cardiology

DM: Diabetes Mellitus

T2D: Diabetes type-2

GLYC: Glycaemia

LV: Left ventricle (ventricular)

BW: Body weight

BH: Body height

QT: The interval between the starting of the Q wave to the end of the T wave in the ECG QTc-QT corrected by heart rate (Bazet formula)

Tpeak: The peak of the $\mathrm{T}$ wave in the ECG

Tend: The end of $\mathrm{T}$ wave in the ECG 